\title{
It's time to (climate) change the way we teach
}

\author{
Addressing anthropogenic climate change \\ in social science classrooms
}

\section{Eleanor Shoreman-Ouimet}

\begin{abstract}
This article outlines pedagogical practices and methodologies for increasing student engagement in the classroom and in the broader community on the topic of climate change. The emphases are placed on (1) preliminary assessments of student understanding and emotional responses to the topic of climate change, (2) assignments that enable student groups to assess and increase campus-wide awareness of various aspects of climate change, and (3) public engagement and service-learning opportunities that allow students to expand their impact beyond the local campus and into their broader community. These practices have proven effective, for large format lecture courses as well as smaller seminar-style courses, in encouraging student participation, overcoming apathy and motivating student effort and action far beyond what can be stimulated by traditional classroom assignments and assessments.
\end{abstract}

\begin{abstract}
KEYWORDS
climate change education, environmental grief, infographics, large format education, non-disposable assignments (NDAs), service learning, social science education, student motivation
\end{abstract}

For years at the large state university where I teach, I watched groups of students present to their peers information and research on specific aspects of climate change. Topics ranging from $\mathrm{CO} 2$ emissions to Coral Bleaching, Climate Refugees and Environmental Justice. Each week of each semester as different groups wrapped up their presentation, they would attempt to motivate behaviour changes among their peers. 'Here's what you can do 
to help', they exclaimed before rattling off a list almost identical to the one presented the week before and inevitably, the week following: 'Recycle, carpool, take shorter showers, walk more, unplug your electronics . . . . And week after week I would ask myself how we have managed to instil such an incomplete message to our students about the reality of their role in global climate change.

Is it important to recycle, carpool, unplug, etc.? Of course it is. Students in my courses are urged to follow the mantra: 'Lead by example - It's contagious!' because everything each of us can do matters and models climatefriendly behaviours to those around us. But that being said, how did this generation of undergraduates come to see themselves as the bad guy? The committing party? The generation responsible for solutions? And what must be the cumulative emotional impact of such environmental guilt and grief?

Some will misinterpret what I am saying and assume that I am letting these students off the hook or that I am dismissing their motivation for change. On the contrary, I think the message they are receiving is incomplete and their efforts, energy, and aspiration to mitigate climate change are largely being thwarted. As educators, peers, parents, and global citizens, it is pertinent that we allow ourselves and our students to see the extent to which this 'rhetoric of recycling' acts as a blinder that narrows our vision and distracts us from acknowledging the true extent to which greenhouse gas emissions and their impacts are the product of multinational corporations, wealthy conglomerates and private companies; and, just as importantly, distracts us from the ways our consumption habits subsidise corporate pollution and increases their wealth, while we, and our increasingly climate-weary students, shoulder the blame and responsibility for environmental damage and repair.

Although many aspects of the science of climate change can be observed and/or calculated, understanding the root causes of human behaviour and worse yet, how potentially to modify culturally rooted practices that tie notions of success and wealth to material production and consumption are wicked problems without formulaic solutions. Although methods for understanding the causes of climate change can be taught, the absence of a clean solution can leave students, as it can anybody, feeling overwhelmed, impotent and ultimately ambivalent (Anderson 2013). Thus, teaching climate change in the social sciences today is not effective as a presentation of dispassionate acts, models or statistics. In the majority of cases, we are no longer in the business of converting deniers or 'sceptics' into 'believers' (McKeown and Hopkins 2010). Lecturing, examination, and traditional, rote 
assignments can aid students' memorisation, but the topic of anthropogenic climate change requires a different level of immediate action and engagement - not simply because all life is in peril, but because emotionally and intellectually, students desire and respond to opportunities to take effective action in the name of mitigating climate change (Anderson 2013; Ariely et al. 2008; Chalofsky and Krishna 2009; Pink 2011; Seraphin et al. 2019).

In my experience, when teaching climate change in a social science setting, especially in large-format lecture classes, it can be a challenge to find or create opportunities for students to 'do more than sit there'. But this is exactly what students are regularly requesting, and this may be one of the few ways to expose students to the realities of the causes, impacts, and potential solutions to anthropogenic climate change. Students want to use their communicative reach to educate and motivate their peers. Students are motivated, especially in the context of climate change and all of its human and ecological consequences to, as David Wiley (2013) phrased it, participate in 'activities which actually add value to the world'. As a means to this end, Sally Seraphin and colleagues (2019) discuss the value of non-disposable assignments (NDAs), or activities that students are asked to engage in as part of an organised course that promotes student learning through the completion of the assignment and affords assessment of students' learning while, most importantly, impacting or adding value outside of the traditional student-teacher dyad. NDAs are believed to help students find 'value, meaning, purpose, identity, competence, and autonomy'. NDAs are thus considered an improvement upon traditional, 'disposable' assignments, which are submitted to the instructor for evaluation but have no broader impact beyond a student's grade (Jhangiani 2015, 2017).

In the remainder of this article, I discuss some of the ways I have attempted to effectively inform, motivate, and gauge the understanding and emotional reaction of students in large format social science lecture settings in the context of climate change. I have designed alternative assignment structures, such as NDAs, that enable students innovatively to educate their peers and community on the causes and impacts of climate change. I have also helped students recognise the very real power they possess to make significant changes towards the mitigation of climate change. The following is an analysis of a pedagogical effort to provide these opportunities to students and an analysis of their efficacy in motivating learning and community engagement. 


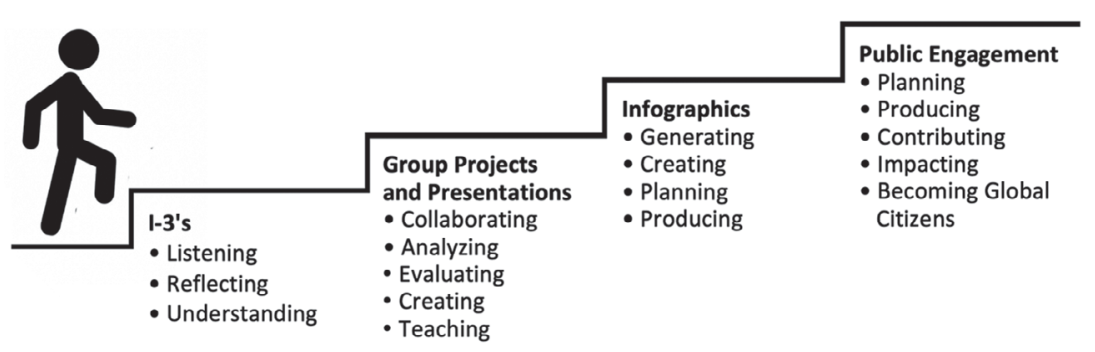

Figure 1. Four aspects of course design that can promote student growth.

\section{Teaching tools and techniques}

I have used three primary tools in different combinations, depending on the size and level of the course, to promote student engagement with content, classmates, and community. The courses in which these assignments and activities have been used include a 125-person Anthropology course on Climate Change and Global Society and an upper level, twenty-person course on Culture and Conservation. The assignments include: (1) I-3s: in-class assignments that stand for 'I'm here, I'm listening, I'm thinking'; (2) infographics and group ethnographic projects for which student groups assigned specific topics create graphic representations of climate change information for public dissemination based on data collected from ethnographic interviews with peers; and (3) public engagement/service-learning assignments. Below I will outline how these NDAs are used and the functions they play in students' absorption, understanding and mastery of concepts. Figure 1 below outlines four aspects of climate change course design that have proven to be an effective pedagogical stratigraphy for promoting student growth. I highlight three of these innovations in greater detail below.

\section{Step One: I-3s 'I'm here, I'm listening, I'm thinking'}

At a large state university, even courses on topics as complex and multifaceted as climate change are often taught in large lecture halls with well over a hundred students, without scheduled opportunities to meet in small groups to discuss questions, emotions, and confusion. Many faculty struggle with maintaining student engagement in such large groups or determining when 
students are misunderstanding concepts or having a difficult time dealing with the magnitude of the material. In trying to address how to help guide large groups of students, many of whom have never taken a course on the material before, I developed short exercises called I-3s, which stand for 'I'm here, I'm listening, I'm thinking'. I-3s are in-class assignments that students complete on small pieces of paper or index cards and include three questions or comments based on class material. I-3s allow students to ask questions, ponder ideas, or submit comments to the instructor and teaching assistant. Students write these comments or questions during the lecture and turn them in to their teaching assistants and/or instructor at the end of every class period. These comments and questions are read by the instructor and teaching assistant who assess if there are concepts that students are struggling to grasp or emotional responses to particular topics and determine which students might need additional assistance. I have found that I-3s serve a few important functions. They effectively encourage students to not just attend class but be present for class - to pay attention to the material, to engage their mind while considering questions or comments they may have. For grading purposes, I choose to grade I-3s by completion - they are only handed back to students the teaching assistant or I decide needs to be contacted for additional help or clarification. However, because I consider their presence and engagement essential to success, I typically make I-3s worth a significant portion of students' final grade, between 10 and 20 per cent.

I-3s serve as students' first concentrated interaction with a topic and provide the first step on a gradient towards higher-level mastery of material (see Figure 1). I-3s allow instructors to hear from the students themselves, a difficult feat in a large lecture hall, as to how well they are emotionally and intellectually processing the information provided. This type of information is critical in understanding how to motivate student action outside the confines of a lecture hall, as well as how best to proceed in the presentation of subsequent material. As professors discussing the reality of climate change, we must take into account the reality that students may be grieving over much of the presented material. These topics can be frightening, disempowering and disheartening to students, especially those who have not had much exposure previously. 


\section{Ethnographic interviews, data analysis, infographics and social media}

As is so often the case with large format lecture courses, there is a lot of material to cover in a relatively short amount of time, especially when that time is divided among so many students. In addition to keeping tabs on students' comfort with the trajectory and scope of the class through I-3s, it is important to enable students to gain mastery of material and, as we all know, there is no better way to master material but to teach. Thus, in my 125-person Anthropology course on Climate Change and Global Society, students are divided into groups of four to six (see Figure 1) for which they work together to (1) examine one aspect of climate change in great depth and (2) educate their peers through presentations to classmates and ethnographic interviews and conversations with peers outside of class.

Beginning in the third week of class, one class period a week is devoted to two twenty-minute presentations that correlate to that week's lecture topic. The projects and presentations are broken into four component parts: (1) topic summary, (2) case study that highlights the impact of the topic on humans and the environment, (3) ethnographic interview analysis, and (4) an infographic. While the summaries and case studies largely function to educate the class, the ethnographic interviews and infographics are designed to help students to engage their peers outside the classroom, to assess the level of understanding about climate change among the general campus population and produce a tangible tool with which to fill in the gaps of knowledge that the student groups discover. Student groups work together to write questions, which they all are responsible for administering to their peers. The goal is to find out how much their fellow students are familiar with their topic and to determine the areas where their peers could benefit from additional information on the topic. At the class-wide level, the culmination of all the groups' survey results provides a fascinating perspective on some of the reasons students may or may not grasp the reality of climate change. For example, how do students in different majors differ in their understanding of the causes and impacts of climate change? Did they have access to related material in high school? Did they grow up with exposure to the outdoors or witness the devastation of natural disasters first-hand? These trends are frequently topics for discussion during lectures. All of this information helps to paint a poignant picture of where information may be lacking, and also, of what type of information is necessary to better inform the campus community. 

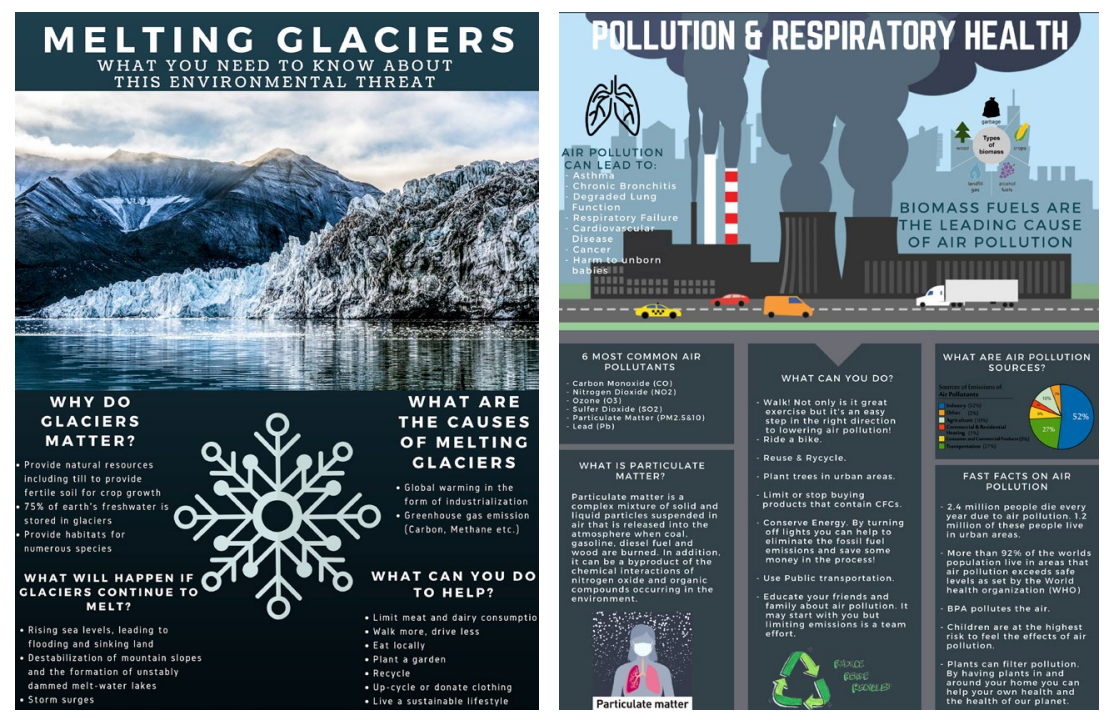

Figure 2. Student infographics on (a) melting glaciers and (b) pollution and respiratory health.

With this data, specifically the information regarding where the student body appears to be lacking in understanding, each group is responsible for creating an infographic on their topics. Infographics are designed to fill in the aforementioned gaps in community-level understanding of particular aspects of climate change and for dispersal on social media; course websites, campus and community websites; and for use at campus and community events. Infographics become students' conduit for framing messages to their classmates and peers about individual and community-level capacity to achieve positive outcomes (Anderson 2013; Morton et al. 2001; Spence and Pidgeon 2010), as well as inform their peers and the general public about the role that specific institutions, industries, companies and corporations play in contributing to and/or remedying climate change, thus helping their peers make educated decisions regarding their own consumption habits and choices. Infographics are an example of a 'non-disposable assignment' (NDA) (Seraphin et al. 2019) that enables students to make an impact beyond the classroom (Anderson 2013). They encourage the creation and the application of metacognitive knowledge, they 'promote self-efficacy by fostering positive evaluation of students' own experiences through the give-and-take of reciprocal evaluative feedback' (Schunk 1989; Schunk and Rice 1987). 


\section{Service learning and public engagement}

Courses addressing issues of climate change in the social sciences are uniquely situated to lead students into the public sphere (Anderson 2013). As part of impactful social science courses addressing climate change, educators can create opportunities for students to collaborate on servicelearning projects. In my upper-level seminars, such as the Anthropology and Environmental Studies course called 'Culture and Conservation', I have assigned such projects to give students the opportunity to apply the theories and methodologies discussed in the classroom and bring them into their community in a myriad of ways, including through interactive blogs, tabling events, elementary and middle school volunteering, assisting community-level projects and cinematography. These projects can also be assigned in large-format classes to expand upon the group work described above in which students delve into the depths of specific climate change related topics and seek to educate their peers on the topic. Student groups that gain a strong understanding of particular topics may then move further beyond the classroom into the broader community. Furthermore, as Seraphin and colleagues (2019: 88) contend, such NDAs are especially well-suited to community engagement that move students beyond simply 'taking' from community members, and casts them as partners in mutually beneficial relationships. Examples from students in my upper level seminar course of twenty students include: videos that highlight the natural surroundings of an area (hiking trails, lakes, rivers, etc.) to increase aesthetic engagement amongst their peers (Yi 2019); community service initiatives to improve local bike and walking paths; Conscientious Consumption blogs with information about how to keep food fresh in apartments and dormitories, how to avoid fast fashion, how to construct reusable shopping bags; and information on cruelty-free, eco-friendly products and companies. Additional student engagement initiatives have included giving presentations at local elementary, middle and/or high schools; running climate action pledge drives in which students and community members sign a pledge committing to take an action to lessen their carbon footprint and consume with a conscience by decreasing their consumption and making purchases from climate-conscious companies (see Figure 3 below). 


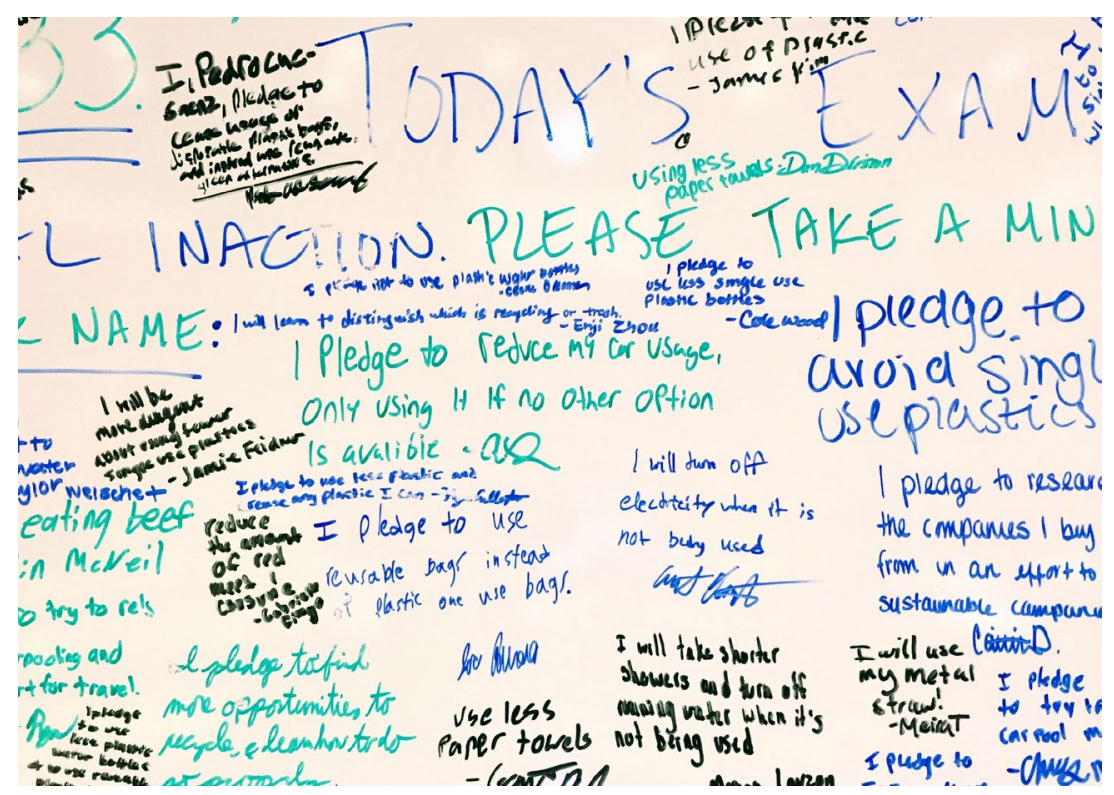

Figure 3. Student Pledge Board: 'Write an action you will take or a change you will make to decrease your carbon footprint and/or that of your community.'

\section{Summary}

In this age of unlimited access to information, misinformation, images, and projected doom, students are coping with often unrecognised grief. They grieve the promise of an earth that can sustain them and their children, they grieve for the struggles of other peoples and species, and they grieve their relatively miniscule ability to take effective action to prevent further environmental and social degradation at the hand of anthropogenic climate change. When this grief is situated in a large lecture hall with over a hundred other students, students have few emotional options beyond disengagement. The wicked problems of climate change are problems with people - human choices, cultural notions of progress and success, and active efforts to prevent the transition away from a waste = profit economy. Thus, as social scientists, trained in the lifeways and behaviour of humans across the globe, we must take steps to not only motivate students but also provide outlets for them to spread essential information and motivation to their peers and broader community. Productive learning exercises that keep lecturers in tune with the students, such as I-3s, combined with NDAs such as ethnographic 
interviews, infographics, and public engagement events, enable students to build critical knowledge and skillsets, while empowering them to use familiar tools such as social media outlets to disseminate their passion and their information (Seraphin et al. 2019). In addition to the benefit of conveying climate change education beyond the classroom, at the end of a semester students feel good about themselves when they see that the time they invest has a positive influence on their environment and community (Allan et al. 2018; Anderson 2013; Ryan and Deci 2000; Vansteenkiste et al. 2004). As a result, students will be more likely to continue the work of climate mitigation and community-level action in the future and walk away with a greater understanding that holding culpable industries, institutions, corporations, and more, accountable via informed consumption choices, voting, and education is an essential part of global citizenship.

Eleanor Shoreman-Ouimet is an environmental anthropologist whose research and teaching focuses on human-environment interactions, environmental justice, cross-cultural conservation practices, community response to natural hazards and the effects of climate change, and the links between culture, history, economics, environmental ethics and resource management. Shoreman-Ouimet is an Assistant Professor of Human and Environment Interactions in the Department of Anthropology at the University of Connecticut, where she teaches a range of large format introductory courses on cultural anthropology, as well as, climate change; and upper-level seminars on environmental anthropology and cross-cultural conservation. Shoreman-Ouimet's recent publications have addressed the study of environmental repair, the influence of anthropocentrism in the social sciences, and facilitating cooperative efforts between anthropologists and conservation groups. E-mail: eleanor.ouimet@uconn.edu

\section{References}

Allan, B. A., R. D. Duffy and B. Collisson (2018), 'Helping others increases meaningful work: Evidence from three experiments', Journal of Counseling Psychology 65: 155-165. https://doi.org/10.1037/cou0000228.

Anderson, A. (2013), 'Climate change education for mitigation and adaptation', Journal of Education for Sustainable Development 6, no. 2: 191-206. https://doi.org/10.1177/ 0973408212475199. 
Ariely, D., E. Kamenica and D. Prelec (2008), 'Man's search for meaning: The case of Legos', Journal of Economic Behavior and Organization 67, nos. 3-4: 671-677.

Chalofsky, N. and V. Krishna (2009), 'Meaningfulness, commitment, and engagement: The intersection of a deeper level of intrinsic motivation', Advances in Developing Human Resources 11, no. 2: 189-203. https://doi.org/10.1177/1523422309333147.

Jhangiani, R. (2015), 'Pilot testing open pedagogy', Rajiv Jhangiani, Ph.D., 23 August, https://thatpsychprof.com/pilot-testing-open-pedagogy/.

Jhangiani, R. (2017), 'Ditching the "disposable assignment” in favor of open pedagogy', Society for the Teaching of Psychology, 2 February, http://teachpsych.org/ E-xcellence-in-Teaching-Blog/4583103.

McKeown, R. and C. Hopkins (2010), 'Rethinking climate change education: Everyone wants it, but what is it?', Green Teacher 89: 17-21.

Morton, T. A., A. Rabinovich, D. Marshall and P. Bretschneider (2001), 'The future that may (or may not) come: How framing changes responses to uncertainty in climate change communications', Global Environmental Change 21, no. 1: 103-109. https:// doi.org/10.1016/j.gloenvcha.2010.09.013.

Pink, D. (2011), Drive: The Truth Behind What Motivates Us (New York: Riverhead Books).

Ryan, R. M. and E. L. Deci (2000), 'Intrinsic and extrinsic motivations: Classic definitions and new directions', Contemporary Educational Psychology 25: 54-67. https://doi.org/ 10.1006/ceps.1999.1020.

Schunk, D. H. (1989), 'Self-efficacy and achievement behaviors', Educational Psychology Review 1: 173-208. https://doi.org/10.1007/BF01320134.

Schunk, D. H. and J. M. Rice (1987), 'Enhancing comprehension skill and self-efficacy with strategy value information', Journal of Reading Behavior 19: 285-302.

Seraphin, S. B., J. A. Grizzell, A. Kerr-German, M. A. Perkins, P. R. Grzanka and E. E. Hardin (2019), 'A conceptual framework for non-disposable assignments: Inspiring implementation, innovation, and research', Psychology Learning \& Teaching 18, no. 1: 84-97. https://doi.org/10.1177/1475725718811711.

Spence, A. and N. Pidgeon (2010), 'Framing and communicating climate change: The effects of distance and outcome frame manipulations', Global Environmental Change 20: 656-667. https://doi.org/10.1016/j.gloenvcha.2010.07.002.

Vansteenkiste, M., J. Simons, W. Lens, K. M. Sheldon and E. L. Deci (2004), 'Motivating learning, performance, and persistence: The synergistic effects of intrinsic goal contents and autonomy supportive contexts', Journal of Personality and Social Psychology 87: 246-260. https://doi.org/10.1037/0022-3514.87.2.246.

Wiley, D. (2013), 'What is open pedagogy?', https://opencontent.org/blog/archives/2975 (accessed 3 June 2021).

Yi, X. (2019), 'Ecological education through aesthetic engagement', Journal of Environmental Education 50, no. 3: 183-191. https://doi.org/10.1080/00958964.2019.1604481. 